\title{
Intrinsic Motivation and Social Constraints: \\ A Qualitative Meta-analysis of Experimental Research Utilizing Creative Activities in the Visual Arts \\ Gloria Sharpless
}

Intrinsic motivation, as defined by social psychologists, is an area of study hampered by mixed and indistinct research findings. This fog-shrouded terrain contributes to a lack of conceptual clarity and creates problems for further research. It also frustrates the translation of research results to classroom practice.

However, the absence of conceptual clarity does not obscure the inherent implications of research findings for the field of art education, primarily because of the creative nature of many of the target activities and the focus on intrinsic motivation. Research implications exist for the field of art education due to the implied (and sometimes stated) link between the social environment, intrinsic motivation and artistic creative performance.

\section{Purpose of the Study}

This qualitative meta-analysis of twenty-seven experimental studies from the fields of psychology and art education focuses on children's motivational responses to the introduction of social constraints. The primary objectives were to identify, examine, and analyze experimental research specifically concerned with the motivational impact of social constraints on the behavior of children two to thirteen years of age participating in creative activities utilizing some visual aspect.

In the initial stage of this investigation I searched the literature from the years 1970 to 1989 for research that met the following criteria for inclusion in this study: (a) published between 1970 and 1989, (b) written in the English language, (c) concerned with intrinsic motivation and social constraints, (d) included creative/heuristic activities utilizing some visual aspect, (e) involved human subjects 2 to 13 years of age (studies using special interest groups were not included), and (f) cited frequently and/or landmark study. These criteria were employed to investigate the relationship between social constraints, intrinsic motivation, and creative performance. This period was selected because during that time some theoretical developments in the field of psychology indicated that external incentives may have detrimental effects on motivation, particularly intrinsic motivation.

The major purposes of this study were to focus on the factors in a social environment that promote and enhance the creative situation, to discover the implications arising therefrom for art education, and to determine

Marilyn Zurmuehlen's Working Papers in Art Education 1993 
where further research needs to be done in order to expand upon the existing research.

\section{The Problem}

The overarching problem is succinctly stated by Csikszentmihalyi (1978): "People who respond exclusively to extrinsic rewards spend their life energies in getting things they did not themselves decide they should want" (p. 208). Thus, people who are aware of why they are involved in any particular endeavor can become more self-determined and free themselves from the kind of control to which Csikszentmihalyi refers.

Brophy (1983) speaks to this problem in his discussion regarding overemphasizing performance in the classroom:

Theory and research on classroom motivation have focused much more on manipulation of task-exogenous factors to control student behavior than on attempts to develop intrinsic motivation by focusing student attention on task-endogenous factors, and much more on motivating students to perform than on motivating them to learn. (p. 206)

This prevailing tendency may contribute to the general failure of the American education system to maintain and enhance intrinsic interest in creative pursuits.

Much of the research conducted by intrinsic motivation theorists has given support to the hypothesis that "extrinsic constraints" can be detrimental to certain aspects of behavior (Deci, 1971; Lepper, Greene, \& Nisbett, 1973).

Other researchers posit that any decrement in intrinsic interest in an activity will be detrimental to creativity (Amabile, Goldfarb, \& Brackfield, 1990). These researchers hypothesize a relationship between the social environment, motivation, and creative behavior. Regarding this hypothesis, Amabile, Hennessey, and Grossman (1986) argue that: "Extrinsic motivation enhances performance on algorithmic tasks ... but undermines performance on heuristic tasks. . . . Because creativity tasks are, by definition, heuristic, they should show adverse performance effects of extrinsic motivation" (p. 15).

Even though much of the intrinsic motivation, and related research, has inherent relevancy for the field of art education, these findings are seldom found in art education literature. This inattention, along with the small number of studies in this area within the field of art education, indicates an information deficiency in the field.

Unfortunately, because of the diverse quality of the studies in the area of intrinsic motivation, it can be an arduous task to translate the research findings to classroom practice. Referring to the disorganized nature of some 
of the research, Eysenck (1984) remarked: "Contemporary cognitive psychology... often seems to resemble the messenger in Alice in Wonderland who went in all directions at once" (p. 1). This multifarious research will not narrow the well known "gap" between research and practice in education.

In order to begin to address these problems, a few of the major questions I asked were:

1. Are social constraints, when introduced to children to promote participation, and often a certain level of performance, in a particular activity detrimental to intrinsic motivation and quality of product?

2. What other factors in the social setting might be contributing to the research findings, especially, the undermining of intrinsic motivation, and the lower quality ratings of the product after the use of external incentives?

3. What might assist someone in becoming more self-determined, i.e., develop an internal locus-of-control (Rotter, 1966), and free oneself from the kind of control to which Csikszentmihalyi (1978) refers?

\section{Overview of Research Method}

I used a qualitative meta-analytic technique to synthesize experimental findings concerning the relationship between social constraints, intrinsic motivation, and creative performance. This qualitative approach brings out aspects that the researchers may have thought were irrelevant or simply ignored about the subject population. "Meta-analysis is aimed at generalization and practical simplicity" (Glass, McGaw, \& Smith, 1981). In addition, the qualitative approach gives one intuitive hunches: lays ground for further studies.

I wanted to analyze the relationships between the variables in these studies and discover possible explanations for the effect(s) of social constraints on intrinsic motivation and creative performance.

My twenty-nine category framework of analysis for experimental research is a version of the one developed by Jones (1980) and was adapted for this study in order to conduct the primary analysis. This analytical approach to experimental research provides a built-in measure for quality control because the selected research has to be thoroughly documented to conform to the framework of analysis and provides some uniformity for diverse data.

The first level of analysis involved partially decontextualizing the data. In order to further review and investigate the data while minimizing any tendency to associate information in familiar patterns, it was deemed necessary to extend the decontextualization. 
This secondary analysis was conducted using the Jones Visually Weighted Free Key Word Indexing System which provided qualitative data analysis. This method was used to organize and categorize the diverse data and to facilitate the discovery of contextual interrelationships within and across the studies. Each study and the framework was transferred onto index cards. Within each category, a color coding and symbol system was developed. These codes allow Boolean, random and probabilistic visual sorts to take place which may either minimize researcher control over a possible outcome or allow the use of the researcher's intuition in formulating the sorts. As these cards evolved, terms, ideas, associations, and interrelationships became apparent. This method of non-quantitative analysis, which encourages a thorough analysis is called "recontextualizing decontextualized knowledge" (Jones, 1980). The analysis of the research, both within and between categories, remains grounded in the data within the original studies.

\section{Conclusions}

The following are general statements concerning the more significant findings and noted limitations.

The experiments often produced contradictory results. Nonetheless, the preponderance of the evidence did reveal that certain social circumstances can decrease intrinsic motivation and, more often than not, adversely affect the rated quality of the creative product (Table 1).

One of the main influences in this regard was the contingency factor. Social rewards that were expected, task-contingent, competitively-contingent, involved no choice or restricted choice, and involved lack of descriptive feedback were more likely to have a negative influence on intrinsic motivation and rated quality of product. In general, performance-contingent rewards, praise (especially descriptive praise), and success were the least likely independent variables to undermine intrinsic motivation and task performance. Even though these conditions would usually not undermine task performance or intrinsic interest, they did not always increase the desired effects. Oftentimes, the findings revealed no effect of conditions on these behaviors.

Of the various theoretical perspectives presented in the studies, each offered a somewhat different orientation for intrinsic motivation. This investigation found more support for Deci's cognitive valuation theory, Amabile's intrinsic motivation hypothesis of creativity, and Bem's self-perception theory. These were also the more frequently tested and funded theories/research. In the 1980 s research designed to investigate and test cognitive evaluation theory and the intrinsic motivation theory of creativity increased. 
Deci (1975) presents three propositions to account for research findings that show a change in the subjects' perceived locus of causality after receiving a reward for performing an intrinsically motivated activity:

(a) intrinsic motivation can be affected by a change in perceived locus of causality from internal to external, (b) intrinsic motivation can be affected by a change in feelings of competence and self-determination, and (c) every social constraint has a controlling aspect and an informational aspect which provide the subject with information about competence and seif-determination ( $p p$. $139,141,142)$. Amabile's (1983) intrinsic motivation hypothesis of creativity maintains that the intrinsically motivated state is conducive to creative performance while the extrinsically motivated state is detrimental. (This hypothesis concentrates on variables related to autonomy.) Bem's (1967) self-perception theory proposes that beliefs are inferred from perception of one's own behavior.

In sum, this study indicated that a context that supports selfdetermination and a feeling of competency will be the most effective way to foster curiosity and exploratory behavior (requisites for creative activity).

This, of course, does not begin to answer the questions raised by the limitations in the selected research. For example, there were not enough data to draw conclusions concerning the persistence of the effects over time, on immediate performance, and on varying levels of initial interest.

In addition, the majority of the selected studies employed research designs that did not directly measure the impact of specific factors from the following variables on intrinsic motivation and task performance:

(a) the subject's reinforcement history, (b) socioeconomic background, (c) personality, (d) demographic information, (e) valuing of the target activity and the social constraint, and (f) the physical environment.

This analysis revealed that there was more room to interpret the influence of affective states than the above variables on the outcome of the research. There seemed to be no clear, strong evidence that the affective states measured were associated with the level of rated creativity or intrinsic motivation. However, there was some support for the affective state of frustration as an explanation for a decrease in intrinsic motivation. Fabes (1987) proposes that instrumental rewards may cue emotions by magnifying the salience of the negative aspects of the situation.

Regardless of developmental differences between younger and older children, the effects of the social constraints on intrinsic motivation and task performance were similar. Overall, the resuits were also similar for the gender factor.

There was also the question of ecological validity. The following were the more consequential shortcomings in this regard: (a) in the majority of the studies the experiment was conducted in physical environments away from

Marilyn Zurmuehlen's Working Papers in Art Education 1993 
the regular classroom, (b) the majority of the studies allowed less participation time than would be the average in a classroom, and (c) the activities were sometimes presented as "play." Ecological validity was also compromised in other studies where the separate research room was referred to as the "surprise room" or the participants were invited to a "party."

Clearly, more research needs to be conducted that will further define under what circumstances social constraints will have a detrimental effect on intrinsic motivation and creativity. These findings could have implications for other disciplines, and could be extended to other environments in society such as the work place. Getzels and Csikszentmihalyi (1976) asserted that if creative behavior is nurtured and encouraged, more people will become better problem-finders and better problem-solvers. This nurturing could produce the necessary creative solutions for social and environmental ills. Therefore, providing environments conducive to creative endeavors should be a high priority in any society concerned with improving the quality of life by identifying significant problems and solving them in a creative manner.

\section{References}

Amabile, T. M. (1983). The social psychology of creativity: A componential conceptualization. Journal of Personality and Social Psychology, 45. 357-376.

Amabile, T. M., Goldfarb, P., \& Brackfield, S. C. (1990). Social influences on creativity: Evaluation, coaction, and surveillance. Creativity Research Journal, 3 (1), 6-21.

Amabile, T. M., Hennessey, B. A., \& Grossman, B. S. (1986). Social influences on creativity: The effects of contracted-for reward. Journal of Personality and Social Psychology, 50, 14-23.

Bem, D. J. (1967). Self-perceptions: An alternative interpretation of cognitive dissonance phenomena. Psychological Review, 74, 183-200.

Brophy, J. (1983). Conceptualizing student motivation. Educational Psychologist, 18 (3), 200-215.

Csikszentmihaly, M. (1978). Intrinsic rewards and emergent motivation. In M. R. Lepper \& D. Greene (Eds.), The hidden costs of reward ( $\mathrm{pp} .98-$ 125). Hillsdale, $\mathrm{NJ}$ : Lawrence Erlbaum.

Deci, E. L. (1975). Intrinsic motivation. New York: Plenum Press.

Eysenck, M. W. (1984). A handbook of cognitive psychology. Hillsdale, $\mathrm{NJ}$ : Lawrence Erlbaum.

\section{Marilyn Zurmuehlen's Working Papers in Art Education 1993}


Fabes, R. A. (1987). Effects of reward contexts on young children's task interest. The Journal of Psychology, 121 (1), 5-19.

Getzels, J. W., \& Csikszentmihalyi, M. (1976). The creative vision. New York: John Wiley \& Sons.

Glass, G. V., McGaw, B., \& Smith, M. L. (1981). Meta-analysis in social research. Beverly Hills: Sage.

Jones, B. J. (1980). Non-quantitative data analysis. Unpublished lecture, University of Oregon, Eugene.

Lepper, M. R., Greene, D., \& Nisbett, R. E. (1973). Undermining children's intrinsic interest with extrinsic reward: A test of the "overjustification" hypothesis. Journal of Personality and Social Psychology, 28 (1), 129-137.

Rotter, J. B. (1966). Generalized expectancies for internal versus external control of reinforcement. In G. A. Kimble (Ed.). Psychological monographs: General and applied (pp. 1-28). Washington, DC: American Psychological Association. 

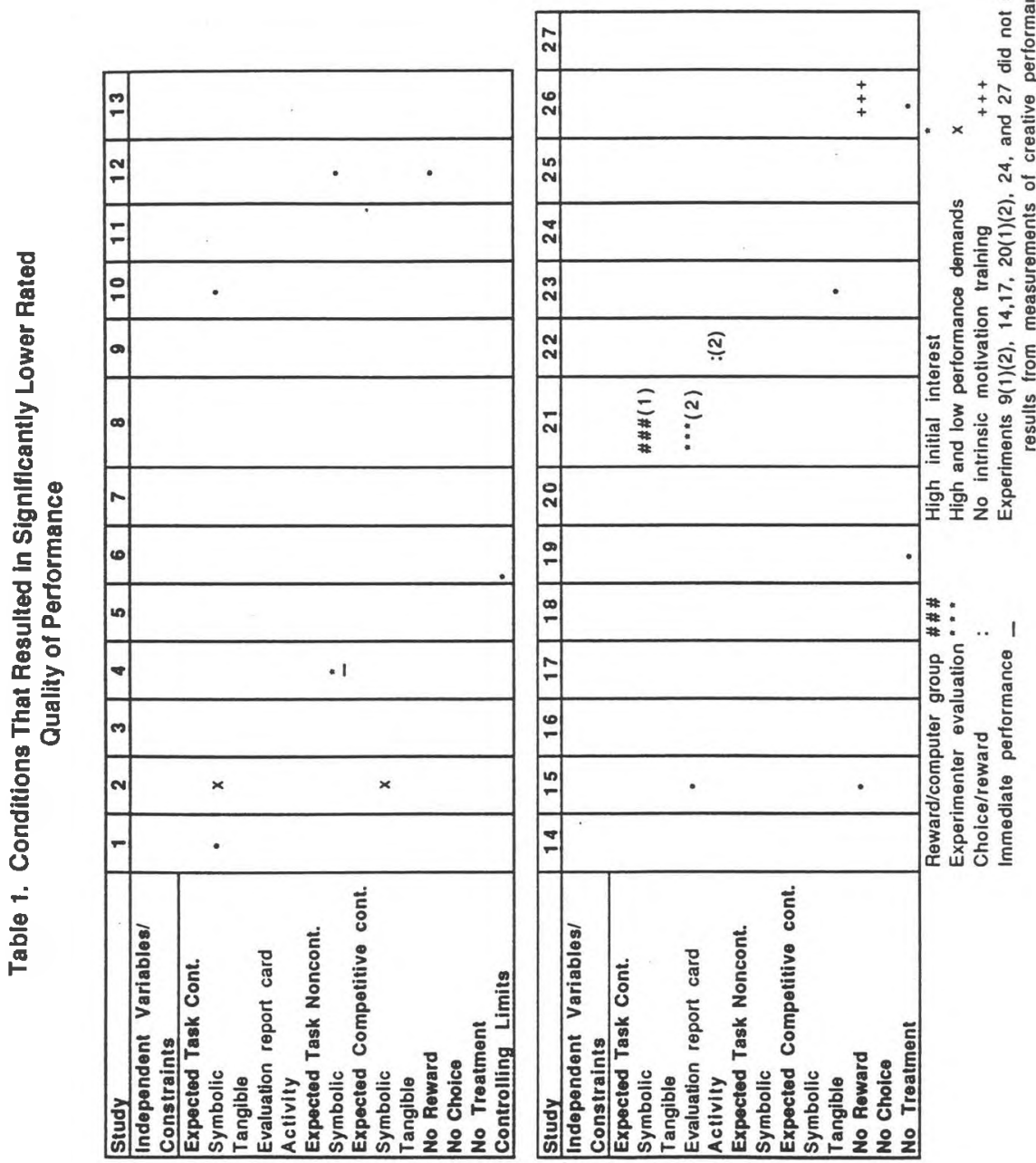